\title{
The Object of Knowledge: The Role of Objects in Biomedical Innovation
}

\author{
by
}

\author{
Jacky Swan, Mike Bresnen, Sue Newell, Maxine Robertson
}

The final, definitive version of this paper has been published in Human Relations, 60/12, 2007, by Sage Publications Ltd, All rights reserved. (C) The Tavistock Institute, 2007. It is available at http://hum.sagepub.com/.

\begin{abstract}
Understanding innovation in the biomedical field requires an appreciation of its highly interactive nature and of the many professional and organizational boundaries that create barriers to interaction and the sharing of knowledge. Yet, research to date has directed much less attention to understanding the intricacies of interactive biomedical innovation in practice, than it has to exploring the factors influencing innovation at an institutional level. Drawing upon empirical research and taking an approach informed by symbolic interactionism and a practice-based perspective on knowledge and learning, this paper offers insights into the processes involved in supporting knowledge sharing by focusing on 'objects' and the varying roles they play (instrumental and symbolic) in enabling (or potentially disabling) interaction amongst groups and organizations involved in biomedical innovation projects.
\end{abstract}

\section{Key words}

Innovation, boundary objects, biomedical, symbolic interactionism, practice-based perspective

\section{Introduction: The problem of knowledge in biomedical innovation}

High levels of failure in innovation in the biomedical domain have led to increased efforts to improve the translation of scientific knowledge into new forms of medical treatments and practices (CMR International, 2006). However, even where the application of scientific knowledge to new treatments has been 'proven' through clinical trials, uptake rates are 
sometimes poor, as it can be difficult to convince medical and health practitioners to change their existing practices (Dopson, 2005; Newell et al, 2003). Such problems arise from the highly complex and iterative relationship that exists between scientific discovery and medical practice. Indeed, existing research has recognized not only the increasingly 'interactive' character of biomedical innovation (Swan et al, 2007), but also of innovation processes more generally (Coombes et al., 2003; Etzkowitz and Leydesdorff, 2000). Biomedical innovations are thus found to be typically highly multidisciplinary, occurring at the interstices between specialist communities and organizations and so traversing institutionalized structures governing the production of knowledge - via, for example, professions, firms, educational systems and institutionalized career paths (Owen-Smith and Powell, 2004).

The ability to traverse 'knowledge boundaries' - boundaries created by specialized practice is, therefore, identified as particularly important for biomedical innovation (Carlile, 2002; Dodgson et al, 2005). Some innovations are also quite radical - they have the potential to profoundly change medical practice (Bock et al, 2003) - and so generate shifts in, or challenges to, the distribution of knowledge and power within and across specialist domains and organizations (Henderson et al, 1999; Christensen et al, 2000). They therefore engender resistance (or enthusiasm) from those implicated in their use (Martin, 2004; Swan et al, 2003). The problems for biomedical innovation, therefore, concern not simply the transfer of artefacts (e.g. patents, new drugs, medical devices), but also the integration of knowledge and information across a distributed network of professional and organizational groups (OwenSmith and Powell, 2004; Powell et al, 2005).

Such problems have not gone unnoticed by policy-makers and practitioners, with initiatives being introduced that seek to deploy more interactive forums for innovation that involve 'heterogeneous users' and the creation of 'knowledge through use' (Gibbons et al, 1994). However, the analysis of new knowledge production within the sector has tended to remain largely at an institutional level (e.g. Casper and Kettler, 2001; Owen-Smith and Powell, 2004). Valuable though this work is in identifying the factors influencing biomedical innovation, it still leaves much to be learned about the detailed mechanisms and processes involved in overcoming (or perhaps reinforcing) knowledge boundaries.

The aim of this paper, then, is to offer insights into the processes involved in supporting knowledge sharing in biomedical innovation. We do this by focusing on the role of 'objects' 
in overcoming knowledge boundaries in interactive innovation forums. Boundary objects have long been seen as an important means of translating knowledge from one specialist knowledge domain to another (Star and Griesemer, 1989; Henderson, 1991; Star, 1989; Carlile, 2002; Bechky, 2003). They can be both concrete objects and abstract concepts (Star and Griesemer, 1989: 393), but their common and defining characteristic is that they contain some 'interpretative flexibility' (Bijker et al., 1987) that allows them to be used to provide a common frame of reference for communication across different domains of knowledge and practice. They are therefore potentially of great significance in helping to understand innovation processes in fields as interactive as biomedicine.

In this paper, we examine the role of objects by drawing specifically upon Carlile's (2002, 2004) framework which distinguishes between three kinds of knowledge boundary syntactic, semantic and pragmatic - and which examines the effects that objects have in enabling, respectively, the transfer, translation and transformation of knowledge (Carlile, 2004: 558-9). However, the paper seeks to contribute further by complementing this analysis of the instrumental effects of boundary objects, with an exploration of their symbolic value in mobilizing commitment to joint action. Drawing upon insights from symbolic interactionism (cf. Prasad, 1993), this paper aims to contribute towards a more robust understanding of the role of boundary objects in general, as well as in biomedical innovation processes more specifically.

The remainder of the paper is structured as follows: first, we outline, in broad terms, our theoretical stance on knowledge and objects. Next, we discuss the roles of objects in mitigating knowledge boundaries. Then we describe our research methods and use our empirical material to illustrate the roles of objects in biomedical innovation using case vignettes. Our analysis suggests, in particular, that, in such contexts, knowledge may itself serve as an important 'meta-level' object of symbolic value in mobilizing commitment towards common project goals and in acting as a means of translating and transforming knowledge at semantic and pragmatic boundaries.

\section{Theoretical background}

Our analysis of objects below draws from well-established theories of social constructivism, and related perspectives on symbolic interactionism (Blumer, 1969), together with more 
recent 'practice-based' perspectives on knowledge and learning (Cook and Brown, 1999). A fundamental tenet of these approaches is that knowledge (or what counts as knowledge) does not exist independently of social relations and social practices but is embedded in social interaction and situated in local practices.

\section{Symbolic interactionist perspectives}

Symbolic interactionist approaches are premised on constructivist notions that social interaction takes place within an enacted social structure (Scott, 1998; Weick, 1979), or "an organized system of symbols and meanings that facilitates exchange among a set of social actors” (Lamertz et al, 2003). From this perspective, enacted social structures are negotiated sets of agreements, rules of conduct and role expectations that emerge as actors 'work out' the terms of their engagement. These then serve as interpretive frames that guide (but do not determine) future actions (Douglas, 1986). Thus, the emphasis in such approaches is on the ways in which social actors interpret each other's conduct as participants in a process of exchange, and develop commonly accepted labels for objects in their environment (Barley and Tolbert, 1997; Bijker et al, 1987).

Relating this to biomedical innovation, a symbolic interactionist approach would highlight the need to focus on ways in which actors engaged in different 'thought worlds' (Dougherty, 1992) come to negotiate new meanings around particular objects, whilst recognizing the social constraints posed by the institutional context in which such negotiations are embedded. Thus, as Garrety and Badham (2000: 104) note: “The creation of stable artefacts is not a preordained process, propelled by the inherent 'rightness' or efficacy of the object itself. Rather, it is contingent, an outcome of complex social interactions”. Objects, then, act as a medium for, as well as an outcome of, social interactions (Prasad, 1993).

Objects include anything to be pointed to, or referred to or agreed upon as an object (Star and Griesemer, 1989: 393). This may include physical objects (e.g. machines, drawings) and also abstract objects (e.g. institutional affiliations, vision statements, theories, epistemologies). As Wenger (1998: 107) observes, boundary objects may be "artefacts, documents, terms, concepts, and other forms of reification around which communities of practice can organize their interconnections" (emphasis added). According to this perspective, therefore, knowledge itself could act as an object, in as much as the pursuit of knowledge in whatever 
form (e.g. a new idea or a new product) energises and enables collective activity. As Bartel and Garud (2003: 333) put it in their exploration of narratives as boundary objects: “The critical feature is that they act as common information spaces that enable interaction and coordination without consensus or shared goals”. Provided boundary objects have a common enough structure to enable them to be recognizable in different social worlds (Star and Griesemer, 1989: 393), they create common ground for communication and knowledge sharing by invoking a shared locus of practice that allows the recontextualization of local understandings in joint activity (Bechky, 2003).

Symbolic interactionist perspectives provide a useful lens through which to analyse the role of objects as they highlight the inherent ambiguity of objects and the political struggle amongst actors to defend their interests and claims to knowledge by manipulating the meaning of objects (Weick, 1979; Lamertz et al, 2003). In addition, they highlight the need to consider the symbolic messages, or the 'sign value' conveyed by objects (Prasad, 1993). Thus, objects play a role in conveying symbolic messages that may have as much, if not more, of an impact on action as more instrumental messages (Feldman and March, 1981). This can, in turn, not only help reduce resistance to an innovation (Prasad, 1993), but also increase it. For example, the attachment of overly positive meanings to new management ideas may generate unrealistically high expectations amongst users, making disappointment almost inevitable (Benders and van Veen, 2001). Whilst symbolic interactionism is premised on the idea that meaning is intrinsically related to action, research studies have tended to focus on meaning and interpretation (Prasad, 1993). Thus, more recent, practice-based perspectives on knowledge and learning, which also recognize the inherent relatedness of knowledge (or knowing) and action, but which focus on practice as the lens through which to view knowing, offer a useful complement to interactionist approaches.

\section{Practice-based perspectives}

Practice perspectives provide important additional insights into the nature and role of objects in innovation (Boland and Tenkasi, 1995; Carlile, 2002). First, they illuminate the relationship between objects, knowledge, work practices, social groups and social context. Practice - defined as "action informed by meaning drawn from a particular group context" (Cook and Brown 1999) - is thus seen as embedded in particular organizational and institutional contexts. Knowledge and learning are localized around problems faced in 
practice and emerge within specialized 'communities of practice' through the improvised responses that individuals make to local problems (Lave and Wenger, 1991). The localization of knowledge within communities of practice, however, whilst vital for learning, also creates boundaries to knowledge sharing across communities. Objects then play a crucial role in mediating the transfer of knowledge and learning across boundaries formed around specialized practice (Henderson, 1991; Bechky, 2003).

Second, where symbolic interactionist views tend to stress the essentially individual nature of knowledge, practice-based perspectives make a distinctive contribution by differentiating those forms of knowledge that are acquired individually and those that are acquired collectively. As Cook and Brown (1999) note, the craft elements of practice are acquired individually but the knowledge of what constitutes 'acceptable' practice is developed and negotiated amongst a particular group or community. Recognizing that there are conflicting views about the value of differentiating between knowledge and practice (cf. Cook and Brown 1999), a third contribution is the emphasis placed on the importance of 'divisions of practice' in establishing boundaries to the acquisition and sharing of knowledge. Brown and Duguid (2001), for example, argue that knowledge flows are channelled by shared work practice, noting that it is "at divisions in practice that knowledge sticks” (p.204).

These situated characteristics make knowledge paradoxical in relation to innovation. On the one hand, the creation of specialized knowledge promotes innovation within communities, allowing knowledge to be applied efficiently to specialized tasks and conditions. On the other hand, knowledge boundaries created by specialization pose barriers to innovation that involves disparate communities (Brown and Duguid, 2001). The ability of objects to mitigate understandings and help in the negotiation of practices across boundaries is therefore particularly crucial. For example, previous work on product innovation in cross-functional settings has noted the effects of boundary objects in transforming understanding at divisions in practice (Henderson, 1991; Carlile, 2002, 2004). However, there is potentially more to be learned from combining an analysis of the instrumental effects of objects with an understanding of their symbolic aspects and of the ways in which the negotiation of meaning and the sign values attached to boundary objects relate to processes of knowledge translation and transformation. 
The work of Bechky (2003), who points out that objects can be used to mobilize action in ways other than for sharing understanding - for example, through signifying status (she uses the example of engineers' drawings) - is indicative. In this case, such objects not only reinforce boundaries, but do so through their symbolic referent power. Levina and Vaast (2005: 354) point further to the emergent nature of 'boundary objects-in-use' and how they acquire the shared symbolic capital that comes with the recognition associated with a joint field of practice. Bartel and Garud (2003: 336) similarly emphasize the importance of the evaluative frame of reference provided by narratives in articulating cultural values and assumptions and in thus providing standards against which individuals working in similar or different contexts can evaluate actions and actors.

In the analysis that follows, we examine the role of objects in biomedical innovation by considering both their instrumental qualities and their symbolic aspects. In a context as highly complex and interactive as the biomedical domain, it may be precisely these more intangible and symbolic aspects that are crucial in creating a shared context for the translation and transformation of knowledge (Carlile, 2002, 2004).

\section{Research Method}

This research uses illustrations drawn from a three year empirical study of the evolution of knowledge in biomedical innovation projects [reference to be added]. This larger study involved detailed longitudinal case studies of ten innovation projects, selected to allow comparisons and contrasts to be drawn between different modes of organizing for innovation across contexts. The innovation process itself constituted the unit of analysis and data collected through interviews was supplemented with data obtained from direct observation at project meetings and from project documentation (including published material).

NVivo was used to code the accumulated data, with the research team meeting regularly to discuss emerging themes. The results of each analytical 'cut' were described using the 'memoing' technique (Glaser, 1978). Each researcher initially tied together different pieces of research material into a recognizable cluster, derived methodological and theoretical/conceptual lessons from the material (Miles and Huberman, 1994) and then sent these to the other researchers for comment. It should be noted that, although our initial 
research questions were not intended to focus specifically on the roles of objects, their importance emerged inductively from the process of analysing the data.

\section{The Genetics Knowledge Park Case}

In this paper we draw upon one of the detailed cases, selected because it provides a good illustration of the knowledge boundaries that we are interested in (Pettigrew, 1990). The innovation involved an attempt to improve the application of genetics knowledge to medical practice. Breakthroughs in genetics have allowed the identification of key signalling molecules that link genomes to specific diseases (called 'targets'). Once specific targets are known, then drugs can feasibly be produced for specific patients ('designer drugs'). Genetic diagnostic tests and screening can also be used to identify patients that are either likely to benefit from a drug, or suffer adverse drug reactions. The challenges of developing such novel technologies for 'pharmacogenetics', however, are great, with functional genomics aimed at finding the best targets for drug development - being heralded as the 'biggest challenge facing drug developers in the post genomics world' (cfFT2003Genomics22).

Responding to this challenge, the UK government in 2001 allocated $£ 15$ million to support six regionally based 'Genetics Knowledge Parks' (GKPs). These GKPs would ensure that the National Health Service (NHS) would be better placed to exploit the findings of genetics research through three major strands of activity: research and training; business development; and public engagement "in a range of ethical, legal and social issues associated with developments in human genetics” (DoH, 2002).

Interviews were conducted with GKP Directors and managers across the six GKPs, and extensive published information on this initiative was collected. This background data was supplemented with a detailed examination of the operations of one GKP and, within this, one innovation project currently underway. The project selected had begun in 2004 and involved evaluating the clinical benefit of genotyping patients for a particular enzyme involved in the metabolism of an immunosuppressant drug prescribed for a wide range of autoimmune diseases. This was to be achieved through a prospective randomized controlled trial, spread across three clinical areas (gastroenterology, rheumatology, dermatology) and conducted on 1,000 patients, recruited from treatment centres across the region. Interviews were held with 15 project team members, who were asked about their involvement, the project's origins and 
development and its organization and management. Interview data were supplemented with documentation and observation of monthly project meetings. The fieldwork lasted 18 months.

According to those involved, the project represented the first attempt to evaluate the introduction of pharmacogenetics testing in NHS hospitals. It was considered highly innovative in its attempt to provide a comprehensive assessment of a wide range of factors associated with the treatment - including not only clinical effects, but also economic aspects and patient preferences. It was also highly interactive, involving experts drawn from a wide range of medical and other disciplines from across the hospitals and universities linked to the GKP:

\footnotetext{
"What became very clear straightaway was that this was a complex problem that would involve a whole range ... of different groups, because it really needed to bring in pharmacy and their ... pharmacological testing ... It also involved the health economists ... and it also brought in the genetics lab within the NHS who are accredited and can offer clinical testing [and] actually present clinically acceptable results. And it also involved all of the different clinical disciplines that would be involved in prescribing [the drug]” (Director of Genomics Research)
}

What follows is analysis of a series of vignettes, selected from the case to illustrate the varied roles that objects can play in interactive biomedical innovation projects at different kinds of knowledge boundary. We draw, in particular, on the boundaries identified by Carlile (2002, 2004) as syntactic, semantic and pragmatic (discussed further below). Case vignettes are not intended as an empirical test of research propositions or questions but, rather, as illustrations and exemplars of particular concepts and/or events (Carlile, 2002). However, their common grounding in one particular case does enable a more complete understanding of the context in which these events occurred and of the processes of collaboration involved. The next section presents and discusses each vignette in turn as it relates to each type of knowledge boundary. A summary of this analysis is presented in Table 1 below, which outlines the instrumental and symbolic effects of each object and their consequences for joint practice.

\section{TABLE 1 ABOUT HERE}




\section{Exploring the role of objects in interactive biomedical innovation}

\section{Syntactic boundaries and objects}

Drawing from a practice-based perspective, Carlile (2002) describes syntactic boundaries as the differences across social communities created by divergence in grammar, symbols, labels and languages. Here, the problem of knowledge integration amounts to being able to 'match differences' across boundaries by using a common syntax between the message 'sender' and message 'receiver' that allows individuals to represent their knowledge to one another. Where a common syntax is established (e.g. through a shared taxonomy or language), then the movement of information across the boundary is fairly straightforward, the challenge effectively reducing to one of increasing information-processing capacity (Carlile, 2004: $560)$.

At the syntactic boundary, objects such as 'knowledge repositories' (Carlile, 2002: 453; Star and Griesemer, 1989: 410) are often used to develop a common syntax. However, a common syntax does not necessarily mean that actors understand objects in exactly the same ways. At the syntactic boundary, objects "do not convey unambiguous meaning, but have instead a kind of symbolic adequacy that enables conversation without enforcing commonly shared meanings” (Boland and Tenkasi, 1995, p. 362). For example, a knowledge repository, such as a shared database, may establish common practices across organizational boundaries for structuring information, which might, in turn, promote knowledge transfer (Briers and Chua, 2001). However, it does not mean that information taken from the database will be interpreted and deployed in the same ways by different groups.

\section{Case vignette \#1: Setting up a common project database}

Given the wide range of specialists, departments and organizations on the project, considerable emphasis was placed on developing appropriate systems and procedures for managing the project and for integrating the numerous, devolved elements of the work. A full time project administrator had been appointed and, although team members were often in direct contact with one another, regular formal monthly meetings, chaired by the lead investigator, provided the main forum for cross-disciplinary discussion and decision-making. 
At these meetings, a detailed progress report was presented which allowed project progress to be assessed against established milestones and deliverables.

Numerous mechanisms were established to enable communication within the team and with wider constituencies (including the progress report, a project website and a newsletter). Particularly crucial for advancing the work was a common database that could be used for the testing of genotypes and the recording of test data. This was developed by the genetics lab, based upon their own general routines for processing samples and recording test data - but customised to meet the specific needs of the project:

"We need to communicate with other members of the team who do not have access to the [lab’s] database ... [Also] the [project] samples need some specific thing to be done, like the randomisation, which is not a routine thing ... We can't accommodate those things into the general [lab] database. So we had to make an additional database to incorporate all these modifications” (Genetics Lab Technician)

The development of a bespoke genotype testing protocol and database constituted an important object in this project - providing an accepted mechanism through which subgroups were able to share and assess information and knowledge about the project. As such, it provides a good example of the role of objects at the syntactic boundary: the lab specialists needed to be able to present clear and valid results to the research scientists without compromising their existing testing protocol or databases; the research team needed to access the results of the tests in order to conduct further (statistical) analyses; and the clinicians needed to be provided with sufficient clinical data for their follow-up consultations with patients. However, although the specialists involved needed to share this information, they did not necessarily understand, nor need to understand, each other's specialist knowledge base. As one respondent put it:

"We have separate mini-meetings because they are quite technical, and we don't get time in the big meetings to discuss things in enough detail ... The project feels quite coherent to me because everybody has an idea of what everybody else's roles are, and some of these areas are quite specialized ... [Others] have their own technical "doing” conversations, and then they bring their deliberations to the group. We have to trust 
that they know what they are doing [but] most of us have sufficient overlap into each other’s areas so we are not just blindly following” (Senior Lecturer, Pharmacy)

Consequently, the development of a common database was one of a number of key mechanisms that contributed towards a common syntax, enabling information to be transferred across the team, whilst work on the project continued in a highly devolved fashion. Moreover, the use of a customised database had a number of important symbolic effects. As the earlier quote suggests, the testing protocol and associated data-processing were considered valid (even if other specialists did not understand how they were produced) because they were undertaken by an accredited laboratory with expertise in genotyping. The results, therefore, would be seen as 'scientifically robust'. Furthermore, the fact that the laboratory had national standing but was keen to provide customized support and resources to the research led to modified systems being developed for the project, which, in turn, symbolized not only an over-arching concern with maintaining rigorous testing methods (so contributing towards the 'scientific legitimacy' of the project), but also a commitment to regional collaboration amongst scientists and clinicians (as reflected in the broader aims of the GKP).

\section{Semantic boundaries and objects}

Semantic boundaries refer to differences in accepted interpretations and meanings amongst actors (Carlile, 2002). Symbolic interactionist research recognizes different interpretations as naturally occurring from divisions in knowledge and practice (e.g. Dougherty, 1992). At semantic boundaries, the critical issue for sharing knowledge is one of 'perspective taking' the process whereby social communities come to recognize and accommodate differences in interpretations such that "the unique thought worlds of different communities of knowing are made visible and accessible to others” (Boland and Tenkasi 1995: 359). Carlile (2002) relates the shift from syntactic to semantic boundaries to task characteristics. As task novelty increases, he argues, differences in the amount or specialization of knowledge that actors possess across a boundary, and the dependencies of actors on one another's knowledge to complete the task, become increasingly unknown (Carlile, 2004: 558). In such circumstances, common syntax may no longer be adequate to transfer knowledge and, consequently, new, shared meanings need to be created that allow the sharing of knowledge (Carlile, 2004: 560). At the semantic boundary, knowledge cannot simply be transferred but needs to be translated, 
so that actors are able to appreciate the differences in knowledge they have by taking on the perspective of the other (Boland and Tenkasi, 1995).

This points, then, to a somewhat different role for objects. At a semantic boundary, objects are needed that help reveal and accommodate differences in perspective and, therefore, reconcile differences in meaning (Nonaka and Takeuchi 1995), thereby helping create a 'common' understanding or objective (Garrety and Badham, 2000) and "a concrete means for individuals to specify and learn about their differences and dependencies across a given boundary” (Carlile, 2002: 451). Drawing upon Star and Griesemer's (1989) original classification of boundary objects, Carlile (2002: 453) identifies standardised forms and methods as being of crucial importance in enabling not simply the representation of knowledge, but also learning, at semantic boundaries.

Attention has also been directed towards the role of social mechanisms for translating knowledge, including the activities of boundary spanners/translators (Carlile, 2004: 560; Wenger, 1998; see also Bartel and Garud (2003) on conferences and workshops). Since objects are themselves social constructs, there is clearly a relationship between individual agency and the translational capability of objects. For example, studies of the development of communities of practice highlight the roles of particular individuals as 'knowledge brokers' or 'thought leaders' (Wenger, 2000). Such actors may be particularly skilled in manipulating the meanings and configurations of objects and social relationships. Objects that can help in translation at the semantic boundary, must, therefore, have the interpretive flexibility to be seen as 'desirable' across groups with very different interests and world-views and knowledge brokers can play a key role in generating commitment to a shared course of action.

This inter-relationship between 'boundary objects in use' and 'boundary spanners in practice' has been shown to be crucial in the emergence and development of joint fields of practice (Levina and Vaast, 2005, Bechky, 2003). For example, Hargadon and Sutton (1997) relate the ability of an individual or organization to act as a broker of innovation not only to their network position, but also to the behaviours and routines used to acquire, store and retrieve knowledge and learning - especially those relating to the use of material artefacts. Pawlowski and Robey (2004) similarly explore how information systems are used by IT professionals as 
boundary objects to facilitate knowledge brokering, highlighting their ability to surface and challenge assumptions and help translate and interpret meaning.

In the first vignette above, differences in interpretation of the system used were not found to be problematic on the project. This was because knowledge dependencies amongst the specialists involved were relatively low: provided the mechanism used for sharing and transferring information was effective and accepted as valid (and this is where symbolic effects were important), differences in understanding did not need to be resolved. Indeed, it was important that the system embodied the lab’s specialized expertise. It also meant that any boundary spanning required (e.g. by the technician who devised the database) was limited to the task of information processing and knowledge transfer (Tushman and Scanlan, 1981). In other types of situation, however, differences in the understandings and interpretations of specialists may clearly pose barriers to innovation, in which case, objects need to allow actors to interpret one another's perspectives on a problem (Carlile, 2002).

\section{Case vignette \#2: Developing data collection instruments}

Although there were certainly examples of differences of interpretation and meaning amongst the core scientific team, these were comparatively rare and considered non-disruptive:

"I'm not an expert in health economics, I'm not an expert in genotyping, but I understand the general principals and know enough to ask questions ... So, generally, there is not a communication problem ... I think we do have a shared vocabulary” (Lecturer, Pharmacy)

However, there was clearly a need to translate complex scientific research questions into detailed practical questions that could capture the information needed for data analysis. Important here were the questionnaires and booklets developed by the team to collect data on clinical outcomes and patient responses to the trial. These data collection instruments comprised an important object that not only captured the range and depth of information sought in the study, but also served as a way of translating the three very specialized aspects of the study (genotyoping, phenotyping and economics/preference work) into a more crystallized and shared view of the project. From the statistician's point of view: 
"The difficult question, I suppose, and this was at the design stage, was how you measure the effectiveness of this test clinically? In economic terms they can do it in terms of pounds and utilities or whatever they want to call them. But in terms of clinical benefit, the difficulty was about how do you measure the clinical benefit? How do you define the clinical benefit? Once you define the clinical benefit, it then becomes a standard two-arm clinical trial” (Senior Lecturer, Medical Statistics)

However, in order to fulfil the research objectives, the patient questionnaires/booklets also needed to contain diverse questions that captured not only factual biomedical information, but also subjective views about the effects of treatment and patient preferences regarding treatment delivery modes. The resultant questionnaires/booklets went through several iterations, with the discussion focusing on what to include and what to omit, how to ask questions and what response categories to use for different types of question. Even more important, however, was the need to design research instruments that were simple and practical enough to be explained to, and used by, patients:

“For the clinical stuff, there's standard questions that you can use and that you're supposed to use because they've been tested and validated ... With these patient-led things, because we're not sure about people's capabilities in filling them in and because the information collected in the diaries is extremely valuable to us, then we need to make it as foolproof as possible. You might imagine that there might be standard ways of collecting this kind of information [but] because health economics is a newer field, there doesn't seem to be more developed [techniques] ... To make sure that everybody interprets what you're looking at as you intended is very difficult, because ... you don't know what the person is thinking” (Project Administrator)

Consequently, the standardized forms for patient assessment had to be designed in such a way that they were flexible enough to meet both the needs of the research and to allow for the practicalities involved. There was therefore a balance to be achieved between the quantity and quality of data deemed desirable and that practically obtainable:

"If you look at the forms that they’ve developed for this study, we've been able to ... help with [the process by] saying, 'Keep it under one page. You know, the doctors will fill it in for you. Keep it nice and simple' ... And similarly with the patient 
questionnaires. Because we do a lot of patient related research here, we've a reasonable idea how many pages of questions a patient will happily tolerate and we've been able to revise a little bit on that and make sure that the questionnaires [work]” (Consultant Rheumatologist)

Furthermore, there was a need to be aware too of the effects of the design of the documentation on those central to the implementation of the study - namely, nurses, who would need to understand what documents were required and how they should be completed:

"If there's a clinical trials unit at the centre ... then we'll liaise directly with the nurses and all the clinicians have to do is fill in the initial [patient] screening form the nurses do the rest ... A lot of the nurses are actually quite experienced ... our forms are fairly straightforward and they're used to the layout. But if they're less experienced ... I made a flowchart for them of what they have to do ... and they keep it in their folder. They may not recruit people on a very regular basis, so they can just pull that out and think 'well, what do I have to do?'” (Project Administrator)

A key element in this process was a consolidated information pack that included this flowchart, together with the information and forms for the screening and recruitment of patients and a set of baseline assessment forms, including the questionnaires and booklets referred to above. These were all based on a standardized protocol amended to suit the needs of the project:

"I designed [the flowchart] and then the other clinicians, we did discuss with them whether it would fit into their usual working practices and that's how we came up with the slight variations, because obviously, if it wasn't workable, it was no use" (Project Administrator)

Consequently, implementing the study involved a translation of meaning to create a shared understanding between the researchers and clinical staff administering the trial about what was involved and how the information was to be collected.

Symbolically, the methods and processes devised to aid in the collection of data clearly signified to those involved a commitment to a multi-faceted and multi-disciplinary approach 
to the research that was designed to gather data across a number of disciplinary fields, with a view to influencing NHS clinical practice directly. Although there was certainly some ambivalence within the team about the extent to which the project represented a 'true' attempt to integrate knowledge (the statistician described it as "a simple two-arm comparison trial with health economics bolted on”), this was tempered by more widespread agreement about the integrative aims of the research as a whole. In other words, differences in meaning and interpretation within the scientific team and between the scientific team and clinical staff were largely overcome with recourse to the translational capacity provided by the objects used, the role of boundary spanners (the project administrator and lead clinician) in articulating the process of research to clinical staff, and with reference to the wider symbolic aims of the project in improving clinical practice as well as contributing towards scientific knowledge.

\section{Pragmatic boundaries and objects}

The role of objects in overcoming divisions in practice that are associated with differences in political interests between those involved has not been extensively studied. A problem with innovation that is highly interactive is that, even if professionals are able to appreciate and understand each other's interpretive frames, it may still be difficult to change practice because of the different interests that impede their ability to share, assess and apply knowledge (Carlile, 2004: 560). Knowledge is invested in practice and so is 'at stake' for those actors who have developed it (Bourdieu and Wacquant, 1992). Where actors have different interests and incentives, knowledge developed in one area may have negative consequences for another and so be resisted. Knowledge integration has also been found to be problematic in multidisciplinary contexts where individuals' work is grounded in different epistemological traditions (e.g. Knorr-Cetina, 1999; Halliday, 1985). Thus, the basis for what constitutes legitimate knowledge varies considerably across disciplines, creating the potential for conflict and pressures to develop alternative ways of defining what constitutes ‘acceptable’ knowledge.

Carlile (2002: 449) defines this type of boundary as pragmatic. According to Carlile (2004), the transition from a semantic to a pragmatic boundary occurs when task novelty and dependency increase (so creating uncertainties), and where actors have different vested interests and incentives (so creating potential conflict). Under these circumstances, the 
interests of one actor may create negative consequences for the other and the shared interpretations developed for dealing with differences at the semantic boundary are insufficient to generate the level of collaboration required. A critical role for objects at pragmatic boundaries is therefore to transform knowledge (Carlile, 2004; Bechky, 2003) - to encourage specialists to translate each other's knowledge and practice, and to transform their own practices as a result.

At pragmatic boundaries, Carlile (2002: 453) identifies maps or models as important. These include various engineering representations and process 'maps' (Henderson, 1991; Bechky, 2003), as well as the 'ideal types' and 'coincident (geo-political) boundaries' originally identified by Star and Griesemer (1989). Objects such as work plans, flowcharts, research proposals and research objectives can help to clarify interdependencies and shape work trajectories (Garrety and Badham, 2000). However, these objects may also be sites for significant conflict. Thus, objects are not uniformly positive in the production of knowledge. As Boland and Tenkasi (1995: 362) suggest: "creating and reshaping boundary objects is an exercise of power that can be collaborative or unilateral”.

\section{Case vignette \#3: Presenting the research to centres and clinicians}

Within the project a clear pragmatic boundary existed due to the different interests that needed to be reconciled between the scientific research and clinical aspects of the study.

"The principal schism, if you like, is between those people involved in the project whose primary responsibility is delivery of the patients [and] the relatively large number of people who are involved with various analytical parts of the project, who are essentially dependent on the clinicians sorting out the clinical recruitment" (Senior Lecturer, Endocrine Sciences)

It was acknowledged from the outset that the project's critical success factor was the recruitment of treatment centres and individual patients and that this depended upon the interface with clinical practitioners, on whose individual diagnostic and treatment practices the study results would most impact. Not only was their commitment of vital importance to the design of the clinical trial and the methods produced, it was also crucial for achieving the patient recruitment levels required. Both of these aspects proved to be problematic. With 
regard to commitment, there was some concern and criticism expressed at the level of engagement of some of the clinicians involved early on in the research, which was at least partly related to the 'internal politics' associated with the bid:

“There's nearly always somebody involved who said they would do something for you and won't do their part, and that's where the tensions are. In [this project] it's the recruiting clinicians at the moment. We had somebody who was going to do some genetic testing for us and then pulled out ... It's commitment to the project that's the issue; it’s not the interdisciplinary bit” (Senior Lecturer, Medical Statistics)

However, of even more importance to the success of the project, and symptomatic of this problem of engaging clinicians, were the practical difficulties experienced in recruiting treatment centres and in then converting centre recruitment into patient numbers:

"My biggest concern challenge-wise is recruitment and just making sure that we can get the number of patients that we need to have the power to really look at the effect that we want to look at ... And making sure that we keep the clinicians engaged and involved in the study" (Consultant in Clinical Genetics)

Indeed, the problem of patient recruitment was one of the few issues that fed back directly into team interaction in a way that resurrected latent epistemic and pragmatic boundaries within the scientific team itself - creating conditions where knowledge was now 'at stake' (Carlile, 2002):

"[We have] to very carefully resist any temptation to give any hints that we might be prepared to accept a lower sample size. The statistician tends to end up being the guardian of the protocol. That tends to be our role, to say, 'this is what you said you would do. You've got to do it. Stop pissing around.' Scientists tend to have ideas, and you can't have ideas once you've designed the clinical trial. You have to do the trial you decided to do, unless there's a very good reason to change it. If you keep messing with the protocol you totally lose credibility” (Senior Lecturer, Medical Statistics)

In recruiting centres, a significant early problem had been encountered due to the need to gain approval from each centre's ethics and R \& D committees, which had created a significantly 
greater amount of work than expected. Once centres were recruited, the main problem was in converting institutional commitment into patient recruitment. Partly this was due simply to the pressures upon busy clinicians. However, it was also due to difficulties in finding an individual at each centre who would take overall responsibility for making sure patient recruitment happened and who could be provided with appropriate incentives:

"If it were a pharmaceutical company sponsored trial, they would be paid a fee, so they could employ a nurse to do it” (Consultant Rheumatologist)

Of crucial importance here were the lead clinician and project administrator - the former, in connecting the team with local clinical practitioners; the latter, in communicating information about the trial to clinical centres and recruiting nurses and in compiling documentation and organizing visits. These two individuals worked together in visiting centres and giving formal presentations about the project to clinicians.

"Usually what happens is the clinicians say 'yes, I'm interested' and either Bruce or myself would go along. The way it's been working out is that Bruce has mainly been going to the gastroenterologists, I'm going to the rheumatologists - just because we've got previous contacts. I usually take them through the forms ... and emphasise that it's not a huge amount of work and they usually take them away to show their nurses, because it's usually the nurses that are having to fill them in” (Project Administrator)

However, there were limits to the role and impact of these individuals as boundary spanners that resulted from the need to devolve most of the work of recruitment to the centres themselves. Consequently, additional mechanisms needed to be devised that would provide the transformational capability required at this division in practice (Bechky, 2003; Carlile, 2004). The forms and methods described in vignette 2 were insufficient for recruiting new centres and incentivising staff to recruit patients. Similarly, the documentation prepared for the purpose of gaining centre committee approvals was fundamentally unsuited to the task of engaging individual practitioners. Moreover, it was clear from the earlier comment about internal politics that the team could not rely upon the original research proposal as a 'boundary-object-in-use' in sustaining later collaboration - however important it had been in engaging key scientific and clinical groups and in obtaining funding. 
Instead, the key objects used to overcome the pragmatic boundary separating the research team from clinical practitioners became the presentations themselves and supporting 'information packs' specifically devised to engage clinicians at these various meetings:

“One of the first things we did was to organize a [project] investigators' meeting which we combined with a meeting to set up a [regional] clinical trials network and this was for the rheumatologists ... We tried to do something for gastroenterologists but we had a poor response, so we had to cancel the meeting. So, the way we tackled engaging the gastroenterologists was Bruce sent out these letters of interest which basically gives a brief overview in a one-page summary of the study ... We also use these [project] information packs. These were given out at the rheumatology investigator's day and Bruce gives them out to people when he goes to see them ... The other thing that we have used is this presentation that we use ... at meetings” (Project Administrator)

Importantly, too, these presentations had symbolic value in the messages they conveyed regarding the value of the research to clinical practice, the contribution to knowledge it represented, the importance of engagement with clinical practitioners and the value of developing expertise within the region. For example, in discussions about how best to motivate individual recruiting staff at each centre, considerable value was placed on emphasising to nursing staff that their 'contribution to scientific research' could be used to good effect in their internal performance appraisals and career development plans. More generally, the presentation and supporting information was used to symbolize a joint commitment to multi-disciplinary, multi-institutional, 'leading edge' research within a regional context that was intended to map not only onto government funding priorities and the GKP research agenda, but also onto local clinical practitioners' needs in improving patient care. Consequently, the use of these presentations as objects was highly symbolic in the ways in which they dealt with the representation of knowledge and in the ways in which they spoke to various internal and external political interests and agendas.

\section{Concluding discussion}


Objects have long been found to facilitate social interactions in innovation processes (Prasad, 1993). Early work tended to emphasize the role of boundary objects and boundary spanners in mediating the sharing and integration of knowledge across semantic boundaries, exploring the ways in which objects can help actors with different perspectives interact and develop shared meanings. The research reported in this paper contributes towards, and extends, such work, by drawing upon practice-based perspectives to unpack the ways that objects mediate knowledge at different kinds of knowledge boundary, including those generated by vested interests (Carlile, 2002).

Biomedical innovation frequently entails high task novelty and dependency amongst diverse actors (Dougherty, 2007). In such contexts, we argue, differences amongst actors in invested practices come to the fore (see also Wenger, 1998; Bechky, 2003; Levina and Vaast, 2005; Pawlowski and Robey, 2004). Our case has demonstrated that, at times, such practice-based boundaries may not need to be overcome: interaction can occur successfully even while those involved do not share the same perspective (as in the genotype testing process and database example). Nevertheless, our case vignettes also provide examples of where practice-based boundaries impeded the innovation process in such a way that there was a need to develop new joint practice to overcome differences in perspectives and interests.

More significantly perhaps, the paper extends the practice-based view by drawing together a view of knowledge as situated in practice with insights from symbolic interactionism. Our case vignettes, though purely illustrative, do nevertheless provide important insights into the ways in which objects may mediate knowledge integration in interactive settings. First, at each type of boundary the symbolic importance of objects appeared to be as important as their instrumental effects. The testing protocol and database, the data collection instruments and the mechanisms used to engage treatment centres and clinical groups were all associated with generally positive values amongst those involved. This was reflected in the ways they dovetailed closely with prevailing discourses concerning, respectively, the need for robust and valid testing methods, the importance of multi-disciplinary and practically-oriented research, and the vision of combining leading edge research with improved clinical practice through the development of regional capabilities.

The positive ideology and values associated with these objects therefore established some legitimacy that was crucial in facilitating interaction. This appeared to be particularly 
important in dealing with problems at pragmatic boundaries (Garrety and Badham, 2000). Developing and using such objects required a good deal of effort by those individuals acting in boundary spanning roles to put across the importance of the research and articulate its basic underlying values. These objects' high interpretative flexibility endowed them with considerable shared symbolic value, which could be leveraged to generate interest in the project and to convince busy clinicians and nurses to take an active part and change their practices.

Although conflict was not a major issue in this particular case, generally in such highly professionalized, multidisciplinary contexts, there is a high likelihood of needing to transform knowledge and to overcome conflict and resistance to change. Here, then, objects may play a particularly important normative role in mobilizing commitment to a particular course of action by conveying broadly based ideologies that, through the construction of new meaning, help communities form around projects and/or reduce resistance to change (Brunsson, 1982). The importance of the symbolic aspects of boundary objects has begun to be explored elsewhere (e.g. Levina and Vaast, 2005). However, an appreciation of the symbolic values associated with objects is typically missing from studies of knowledge and innovation, which focus almost entirely on their instrumental characteristics.

A second observation from our study has to do with the way in which 'knowledge' itself might be constructed as an (abstract) object. For example, with regard to the initiative as a whole, the 'Knowledge Park' vision depicts genetics knowledge as a desirable thing to be pursued through collaboration - as an end in itself, as well as in the interests of 'society'. Moreover, the 'Knowledge Park' metaphor, used quite explicitly here, has high symbolic value. It symbolizes the government's 'message' that advances in the production of knowledge will be achieved through developing new open, regionally based and accessible spaces, where members from different local communities can meet to share knowledge and engage in collaborative work. The 'Park' is thus depicted as a place (with a physical building in some cases) where a new community that embraces scientific, medical, public and commercial constituents can be built around the application of genetics knowledge. Indeed, this notion of 'community building' was clearly expressed in the GKP's own work plans, proposals and public documents. 
Of course, the 'Knowledge Park’ concept is inherently ambiguous - it can mean anything or nothing to those involved, as illustrated by the GKP Director's statement:

"[The government] white paper ... had a page or half a page on knowledge parks. They had to interpret it in some way. I don't think they were given clear guidance themselves. When their ideas started sifting through, after a while it became very clear at that midterm review ... that they didn't know what they were looking for even then. If any one of us knowledge parks was lucky enough to hit the nail on the head, they might have found what they were looking for. But they didn't actually know at the beginning of that process. I'm not all together sure whether they ever did find out.”

However, the interpretative flexibility that this implies, coupled with the importance attached to the generation of knowledge and innovation in contemporary public policy discourse, invests the pursuit of 'knowledge' in GKPs with high levels of symbolic capital. In doing so, it provides a 'tangible definition' (Bechky, 2003) around which groups are able to develop and pursue joint activity (cf. Levina and Vaast, 2005).

Our analysis of innovation within the GKP suggests further that 'knowledge' itself is capable of being formulated as an object (and objective), the desirability of which is unquestioned amongst the professional groups involved. Around the primary object of 'Knowledge Park', other, secondary, objects, such as individual research projects and work plans, are developed that embody the ideological commitment to this particular (accepted) form of knowledge generation. In doing so, they help shape further social interactions and networks that, in turn, positively reinforce the ideology and specific approach to knowledge creation represented through GKPs.

Typically, it is argued that treating 'knowledge' as if it were an object falsely separates knowledge from context and so generates problems for practice (Tsoukas, 1997; Alvesson and Karreman, 2000). However, in interactive innovation, there are significant disagreements over epistemic practices and different ways of warranting knowledge (Knorr-Cetina, 1999). Presenting 'knowledge' as a desirable end in itself may act as a powerful primary object that mobilizes changes in practice (Swan et al, 2003). The pursuit of knowledge as an object is in line with observations that objectifying knowledge and, thus, abstracting it from context may 
be necessary for it to become widely accepted (Letiche and van Hattem, 2000). It also resonates with Gherardi's (2003) observations on the motivational effects of a desire to advance knowledge as something that is of value in its own right and not just because it solves problems.

A third observation from our study more generally concerns the multi-faceted role of objects in relation to the development of social practices and social boundaries. In the case of the GKP innovation project, the objects explored were important in encouraging collaboration and knowledge sharing. However, this is not to say that such objects may not simultaneously create boundaries to collaboration and knowledge sharing at another level or in another context. Thus, 'boundary spanning' objects can, at the same time, be 'boundary creating' objects, especially where the boundary in question is based on practice (Scarbrough et al, 2004). Relevant examples here are the very project-specific objects, such as the customised database or information pack, which, while they aided collaboration within the team, did so by reinforcing the distinctiveness of the project from other tasks. This observation has been made elsewhere (Carlile, 2002: 451-2; Levina and Vaast, 2005: 340) and is an important counterfoil to existing literature that highlights the almost uniformly positive role of objects in brokering knowledge and relationships. Objects may serve to create a unifying influence and focus for collaboration and convergence of local practices. However, they may also simultaneously signify and reinforce the distinctiveness of different collaborative relationships, in ways that reflect the particular constellations of competencies, orientations and interests observed.

Finally, the perspective offered here has the potential for exploring more fully some of the more complex and sublime processes associated with interactive innovation, such as shifts in power/knowledge and attendant changes in occupational practice and identity. Alternative perspectives on objects - such as Actor Network Theory (Latour, 1987) - could, of course, be used to shed further light on, for example, the political process involved in innovation (Garrety and Badham, 2000). However, symbolic interactionist and practice-based perspectives emphasize precisely, and quite explicitly, the kinds of multiple perspectives, ambiguous interpretations and diverse practices commonly encountered in radical, interactive innovation settings. Whereas ANT tends to presume a central, more powerful actor within network configurations and to 'fix' (temporarily) objects in their identity (as 'actants'), symbolic interactionist and practice-based perspectives stress instead the inherent ambiguity 
of social situations, including ambivalence around the meanings (or multiple meanings) of objects, roles and identities. In interactive innovation, considerable uncertainty and ambivalence revolves around basic questions concerning the nature of social and professional practices and relationships (Dougherty, 2007). Key questions, such as 'what are we doing?', 'what do we hope to achieve?', 'who/what are we doing it with?' and 'what is likely to happen?' form a vital discursive counterpoint to the practices engaged in by actors attempting to develop innovative biomedical products and practices. We argue here that, in taking this approach, a more penetrating examination is possible that allows for understanding how such ambiguities play out in a field as complex as biomedical innovation.

\section{Acknowledgements}

TBA

\section{References}

Alvesson, M. \& Karreman, D. (2000) Odd couple: Making sense of the curious concept of knowledge management. Journal of Management Studies, 38, 995-1018.

Barley, S.R. \& Tolbert, P.S. (1997) Institutionalization and structuration: Studying the links between action and institution. Organization Studies, 18, 93-117.

Bartel, C. A. \& Garud, R. (2003) Narrative knowledge in action: Adaptive abduction as a mechanism for knowledge creation and exchange in organisations. In M. Easterby-Smith \& M. SA. Lyles (eds), The Blackwell handbook of organisational learning and knowledge management, Oxford: Blackwell.

Bechky, B. A. (2003) Sharing meaning across occupational communities: The transformation of understanding on a production floor. Organisation Science, 14(3), 312-330.

Benders, J. \& van Veen, K. (2001) What's in a fashion? Interpretative viability and management fashions. Organization, 8(1), 33-54. 
Bijker, W.E., Hughes, T.P. \& Pinch, T.J. (1987) The social construction of technological systems. Cambridge, MA: MIT Press.

Blumer, H. (1969) Symbolic interactionism: Perspective and method. Berkley: University of California Press.

Boland, R.J. \& Tenkasi, R.V. (1995) Perspective making and perspective taking in communities of knowing, Organization Science, 6(4), 350-372.

Bock, A.K, Ibarreta, D. \& Rodriguez-Cerezo, E. (2003) Human tissue engineered products: Today's markets and future prospects. Report for the Joint Research Centre, European Commission.

Bourdieu, P \& Wacquant, L. (1992) An invitation to reflexive sociology. Chicago: University of Chicago Press.

Briers, M. \& Chua, W.F. (2001) The role of actor-networks and boundary objects in management accounting change: A field study of an implementation of activity-based costing. Accounting, Organizations and Society, 26(3).

Brown, J.S. \& Duguid, P. (2001) Knowledge and organization: A social-practice perspective. Organization Science, 12(2), 198-213.

Brunsson, N, (1982) The irrationality of action and action rationality: Decisions, ideologies and organizational actions. Journal of Management Studies, 19(1), 29-44.

Carlile, P. (2002) A pragmatic view of knowledge and boundaries: Boundary objects in new product development. Organization Science, 13, 442-455.

Carlile, P. (2004) Transferring, translating and transforming: An integrative framework for managing knowledge across boundaries. Organization Science, 15(5), 555-568. 
Casper, S., \& Kettler, H. (2001) National institutional frameworks and the hybridization of entrepreneurial business models: The German and UK biotechnology sectors. Industry and Innovation, 8(1), 5-30.

Christensen, C., Bohmer, R. \& Kenagy, J. (2000) Will disruptive innovations cure health care? Harvard Business Review, Sept/Oct, 102-112.

CMR International (2006) Centre for Medical Research International R\&D Compendium, 2006.

Cook, S.D.N. \& Brown, J.S. (1999) Bridging epistemologies: The generative dance between organizational knowledge and organizational knowing. Organization Science, 10, 381-400.

Coombs R, Harvey M, Tether B.S. (2003) ‘Analysing distributed processes of provision and innovation’, Industrial and Corporate Change, 12(6), 1125-1155.

Dodgson, M., Gann, D. and Salter, A. (2005) Think, play, do: Innovation, technology and organization. Oxford: OUP.

DoH (2001) Development of genetics knowledge park. Tender specification, Department of Health.

DoH (2002) The genetics knowledge parks network - Overview, Department of Health.

Dopson, S. (2005) The diffusion of medical innovations: Can figurational sociology contribute? Organization Studies, 26(8), 1125-1144.

Dougherty, D. (1992) Interpretive barriers to successful product innovation in large firms. Organization Science, 3, 179-202.

Dougherty, D. (2007) Trapped in the $20^{\text {th }}$ century? Why models of organizational learning, knowledge and capabilities do not fit bio-pharmaceuticals, and what to do about that. Management Learning, in press. 
Douglas, M. (1986) How institutions think. Syracuse: Syracuse University Press.

Etzkowitz, H., \& Leydesdorff, L. (2000) The dynamics of innovation: From national systems and “mode 2" to a triple helix of university-industry-government relations. Research Policy, 29, 109-123.

Feldman, M.S. \& March, J.G. (1981) Information in organizations as signal and symbol. Administrative Science Quarterly, 26, 171-186.

Garrety, K. \& Badham, R. (2000) The politics of socio-technical intervention: An interactionist view. Technology Analysis and Strategic Management, 12, 103-118.

Gherardi, S. (2003) Knowing as desiring. Mythic knowledge and the knowledge journey in communities of practitioners. Journal of Workplace Learning, 15, 352-359.

Gibbons, M., Limoges, C., Nowotny, H., Schwartzman, S., Scott, P., \& Trow, M. (1994) The new production of knowledge: The dynamics of science and research in contemporary societies. London: Sage.

Glaser, R., Ed. (1978) Advances in instructional psychology. London: Wiley. 83-84.

Halliday, T. (1985) Knowledge mandates: Collective influence by scientific, normative and syncretic professions. British Journal of Sociology, 36(3), 421-439.

Hargadon, A. \& Sutton, R. I. (1997) Technology brokering and innovation in a product development firm. Administrative Science Quarterly, 42(4), 716-.

Henderson, K. (1991) Flexible sketches and inflexible databases: Visual communication, conscription devices, and boundary objects in design engineering. Science, Technology, \& Human Values, 16(4), 448-473.

Henderson, R., Orsenigo, L. \& Pisano, G. (1999) The pharmaceutical industry and the revolution in molecular biology: Interactions among scientific, institutional, and 
organizational change. In D. Mowery \& R. Nelson (eds), Sources of industrial leadership, pp.267-311. Cambridge: Cambridge University Press.

Knorr-Cetina, K. (1999) Epistemic cultures: How the sciences make knowledge. Cambridge MA: Harvard University Press.

Lamertz, K., Martens, M. \& Heugens, P. (2003) Issue evolution: A symbolic interactionist perspective. Corporate Regulation Review, 6(1), 82-93.

Latour, B. (1987) Science in action. Cambridge, MA: Harvard University Press.

Lave, J. \& Wenger, E. (1991) Situated learning: legitimate peripheral participation. Cambridge: Cambridge University Press.

Letiche, H. \& van Hattem, R. (2000) Self and organization: Knowledge work and fragmentation. Journal of Organizational Change, 13, 352-366.

Levina, N. \& Vaast, E. (2005) The emergence of boundary spanning competence in practice: Implications for implementation and use of information systems. MIS Quarterly, 29(2), 335363.

Martin, P. (2004) Pharmacogenetics: innovations and expectations. ESRC Cultures of the Gene Seminar, University of Warwick, January 2004.

Miles, M. \& Huberman, A. (1994) Qualitative data analysis: An expanded sourcebook. (1994). London: Sage.

Newell, S., Edelman, L., Scarbrough, H., Swan, J. \& Bresnen, M. (2003) 'Best Practice’ development and transfer in the NHS: The importance of process as well as product knowledge. Health Services Management Research, 16, 1-12.

Nonaka, I. \& Takeuchi, I. (1995) The knowledge creating organization. Oxford: Oxford University Press. 
Owen-Smith, J. \& Powell, W. (2004) Knowledge networks as channels and conduits: the effects of spillovers in the Boston biotechnology community. Organization Science, 15(1), 521.

Pawlowski, S. D. \& Robey, D. (2004) Bridging user organisations: Knowledge brokering and the work of information technology professionals. MIS Quarterly, 28(4), 645-672.

Powell, W.W., White, D.R., Koput, K.W. \& Owen-Smith, J. (2005) Network dynamics and field evolution: The growth of interorganizational collaboration in the life sciences. American Journal of Sociology, 110(4), 1132-1207.

Prasad, P. (1993) Symbolic processes in the implementation of technological change: A symbolic interactionist study of work computerization. Academy of Management Journal, 36, $1400-1430$.

Scarbrough, H., Swan, J., Laurent, S., Bresnen, M., Edelman, L. \& Newell, S. (2004) Projectbased learning and the role of learning boundaries. Organisation Studies, 25(9), 1579-1600.

Scott, W.R. (1998) Organizations. $4^{\text {th }}$ Ed. Upper saddle River, NJ: Prentice Hall.

Star, S.L. (1989) The structure of ill-structured solutions: Boundary objects and heterogeneous distributed problem solving. In J. Weschler (ed.), On aesthetics in science, Cambridge, MA: MIT Press.

Star, S.L. \& Griesemer, J. (1989) Institutional ecology, translations and boundary objects: Amateurs and professionals in Berkley’s Museum of Vetebrate Zoology 1907-1939. Social Studies of Science, 19(3), 387-420.

Starkey, K. \& Madan, P. (2001) Bridging the relevance gap: Aligning stakeholders in the future of management research. British Journal of Management, 12, S3-S26.

Swan, J., Goussevskaia, A., Newell, S., Robertson, M., Bresnen, M. \& Obembe, A. (2007) Modes of organizing biomedical innovation in the UK and US and the role of integrative and relational capabilities. Research Policy, 36(4), 529-547. 
Swan, J., Scarbrough, H. \& Robertson, M. (2003) The construction of 'communities of practice' in the management of innovation. Management Learning, 33, 477-496.

Tsoukas, H. (1997) The tyranny of light. Futures, 29, 87.

Tushman, M. \& Scanlan, T. (1981) Boundary spanning individuals: Their role in information transfer and their antecedents. Academy of Management Journal, 24(2), 289-305.

Weick, K. (1979) The social psychology of organizing. Reading, MA: Addison Wesley

Wenger, E. (1998) Communities of practice: learning, meaning and identity. Cambridge:

Cambridge University Press.

Wenger, E. (2000) Communities of practice and social learning systems. Organization, 7(2), 225-46. 
Table 1: Boundaries, Objects and their effects on the Project

\begin{tabular}{|c|c|c|c|}
\hline & Instrumental effects & Consequences for joint practice & Symbolic effects \\
\hline Syntactic boundary & $\begin{array}{l}\text { created mechanism for sharing and assessing test } \\
\text { results across scientific team and clinical groups }\end{array}$ & $\begin{array}{l}\text { required only limited understanding of } \\
\text { techniques used and only minor modifications to } \\
\text { project routines and standard lab practice: } \\
\text { (specialization and 'mini meetings' still needed) }\end{array}$ & $\begin{array}{l}\text { independent, nationally accredited lab signified } \\
\text { rigor in testing and legitimacy of test results } \\
\text { bespoke element signified commitment to project } \\
\text { team and regional agenda }\end{array}$ \\
\hline
\end{tabular}

Developing Data Collection Instruments (flowchart, patient questionnaire and booklet)

\section{Instrumental effects}

Semantic boundary

created shared understanding between research

team, nurses and patients of data collection

process and methods

\section{Consequences for joint practice}

required some modification to standard methods and questions, but only minor effects on project routines and nurses' work practices

\section{Symbolic effects}

signified commitment to multi-disciplinary research, improving clinical practice and meeting patients' needs

signified desire to use valid methods and have minimal disruptive effects on centre treatment practices

Presenting the Research to Centres and Clinicians (information pack)

\section{Instrumental effects}

Pragmatic boundary

created shared understanding between research team and clinicians of project aims and

objectives and provided a mechanism for engaging centres/clinicians in joint activity

\section{Consequences for joint practice}

changed project routines and patient treatment practices

\section{Symbolic effects}

signified a shared vision (consistent with GKP ideals and regional agenda), combining leading edge research with improved clinical practice 